\title{
Parthenolide Inhibits Angiogenesis in Esophageal Squamous Cell Carcinoma Through Suppression of VEGF
}

This article was published in the following Dove Press journal: OncoTargets and Therapy

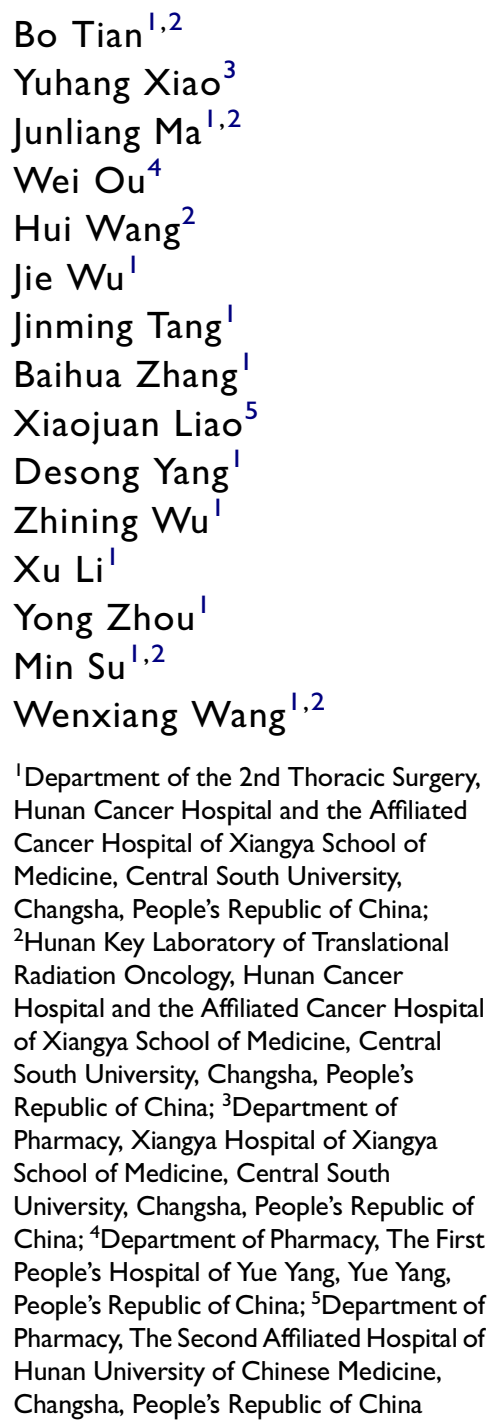

Correspondence: Wenxiang Wang; Min Su

$\mathrm{Tel} / \mathrm{Fax}+86-73 \mathrm{I}-89762110$

Email hnchwlI@I63.com; sumin27@I26.com
Background: Parthenolide (PT), the effective active ingredient of the medicinal plant, feverfew (Tanacetum parthenium), has been used as an anti-inflammatory drug due to its involvement in the inhibition of the NF-кB pathway. Moreover, recent studies have demonstrated the anti-tumor effect of PT in several cancers. However, the effect of PT on esophageal carcinoma remains unclear to date. In this study, we examined the inhibitory effects of PT and its underlying mechanism of action in human esophageal squamous cell carcinoma (ESCC) cells - Eca109 and KYSE-510.

Methods: The proliferation ability of Eca109 and KYSE-510 treated with PT was detected using the Cell Counting Kit-8 and colony forming assay. The Transwell assay and the wound healing assay were used to analyze the cell invasion and migration ability, respectively. The tube formation assay was used to investigate the effect of PT on tube formation of endothelial cells. The expression level of NF-кB, AP-1 and VEGF was analyzed by Western blot.

Results: We demonstrated that PT attenuates the proliferation and migration ability of ESCC cells in vitro and also inhibits tumor growth in the mouse xenograft model. In addition, PT exhibited anti-angiogenesis activity by weakening the proliferation, invasion and tube formation of endothelial cells in vitro and reduced microvessel density in the xenograft tumors. Further studies revealed that PT reduced the expression level of NF-кB, AP-1 and VEGF in ESCC cells. Conclusion: Collectively, the results of our study demonstrated that PT exerts anti-tumor and anti-angiogenesis effects possibly by inhibiting the NF-кB/AP-1/VEGF signaling pathway on esophageal carcinoma and might serve as a promising therapeutic agent for ESCC. Keywords: parthenolide, esophageal squamous cell carcinoma, NF-кB, VEGF, AP-1

\section{Introduction}

Esophageal carcinoma (EC), a malignant tumor originating from the esophageal epithelium, is the sixth leading cause of cancer-related mortality worldwide. ${ }^{1}$ There are two major histological types of EC: esophageal adenocarcinoma (EAC), the predominant cause of EC in the Western countries, and esophageal squamous cell carcinoma (ESCC), the leading histological type in Asians. ${ }^{2}$ In spite of the advances made in clinical diagnosis and multidisciplinary treatment, the overall prognosis of patients with $\mathrm{EC}$ is poor as the 5-year relative survival rate is less than $20 \%$ due to its rapid progression, resistance to radiochemotherapy, recurrence and metastasis. ${ }^{3,4}$ Thus, finding new therapeutic agents and emerging strategies is an urgent requirement for improving the clinical outcome of patients with EC.

Angiogenesis, the outgrowth of new blood vessels from pre-existing ones, has been demonstrated to play an important role in the growth and metastasis of most solid 
tumors. $^{5}$ It is a complex process and involves extracellular matrix degradation, endothelial cell proliferation, migration, invasion, and transformation into tubular structures. ${ }^{6}$ The growth and progression of solid tumors, including esophageal cancer, depend on tumor angiogenesis. ${ }^{7}$ Anti-angiogenesis therapy has also been proven to be an effective strategy for the treatment of solid tumors. VEGF is the main angiogenesis promoting factor; therefore, anti-VEGF treatment is an effective anti-angiogenesis treatment strategy of tumors. Bevacizumab, a human recombinant monoclonal anti-VEGF antibody, is the first anti-angiogenesis drug that had been used for the clinical treatment of various tumors such as lung cancer and breast cancer. ${ }^{8-10}$ In esophageal cancer, bevacizumab is still in the stage of clinical trials currently, but anti-VEGF treatment is a therapeutic strategy worth looking forward to. ${ }^{11}$

Parthenolide (PT, Figure 1A), a natural sesquiterpene lactone, is the main active ingredient of feverfew (Tanacetum parthenium), which is used against fever and inflammatory diseases as phytomedicine. ${ }^{12,13}$ It has been established that PT is a nuclear factor kappa B (NF-кB) inhibitor whose mechanism of action is thought to involve direct binding and preventing NF-кB subunit $\mathrm{p} 65$ protein binding to DNA, and inhibition of the ІкB kinase (IKK) complex, which activate NF-кB by promoting the proteasomal degradation of NF- $\mathrm{B}$ inhibitors$\mathrm{I} \kappa \mathrm{B} \alpha$ and $\mathrm{I}_{\mathrm{B}} \beta{ }^{14}{ }^{14}$ Recent studies have demonstrated that PT exhibits anticancer property in a number of human cancer cells, including breast cancer, ${ }^{15}$ lung cancer, ${ }^{16}$ pancreatic cancer, ${ }^{17}$ and colorectal cancer. ${ }^{18}$ PT has been shown to inhibit proliferation and induce apoptosis in various human cancer cells. Moreover, PT was also shown to inhibit angiogenesis in many tumors. ${ }^{19,20}$ In esophageal cancer, it has been reported that PT can inhibit the proliferation of EC9706 cells and induce apoptosis, ${ }^{21}$ however, there is limited information regarding its anti-angiogenic effect. In the present study, our results demonstrated PT was cytotoxic to Eca109 and KYSE-510 ESCC cells in vitro. PT could also inhibit the ESCC cellinduced angiogenesis, probably through the NF-кB/AP-1/ VEGF pathway. The findings of this study suggested that PT might be a potential therapeutic agent in the treatment of ESCC.

\section{Materials and Methods}

\section{Reagents and Cells}

PT and Cisplatin (DDP) were purchased from Selleckchem (Houston, TX, USA). Tumor necrosis factor- $\alpha$ (TNF- $\alpha$ ) was obtained from Sigma Aldrich (St. Louis, MO, USA). Anti-CD31, anti-Ki67, anti-c-Fos, anti-c-Jun, and anti-NF $-\kappa \mathrm{B}$ antibodies were purchased from Cell Signaling Technology (Danvers, MA, USA). Anti-VEGF and antiGAPDH antibodies were obtained from Abclonal Technology (Wuhan, Hubei, China). The human ESCC lines-Eca109, KYSE-510 and human esophageal epithelial cells Het-1A were purchased from the Cell Bank of the Chinese Academy of Sciences (Shanghai, China). Human umbilical vein endothelial cells (HUVECs) were obtained from Xiangya Central Experiment Laboratory. The cells were cultured at $37^{\circ} \mathrm{C}$ in a $5 \% \mathrm{CO}_{2}$ incubator using Roswell Park Memorial Institute-1640 (RPMI-1640, Basal Media, China) containing 10\% fetal bovine serum (FBS, Biological Industries, Israel), $100 \mathrm{U} / \mathrm{mL}$ penicillin and $100 \mu \mathrm{g} / \mathrm{mL}$ streptomycin.

\section{Cell Proliferation Assays}

Cells were inoculated into 96-well plates (2000 cells/well) and incubated with PT $(0-50 \mu \mathrm{M})$ combined with DDP (5 $\mu \mathrm{M})$ or not for $48 \mathrm{~h}$ after cell adhesion. The absorbance at the wavelength of $450 \mathrm{~nm}$ was detected after $2 \mathrm{~h}$ incubation with $20 \mu \mathrm{L}$ cell count kit-8 (CCK-8, Beyotime Institute of Biotechnology, Shanghai, China).

\section{Colony Forming Assay}

Cells were seeded in 6-well plates at 1000 cells/well and incubated overnight. PT $(0,5,10,20 \mu \mathrm{M})$ was added to the well for $4 \mathrm{~h}$ and the used medium was replaced with a fresh medium. The cells continued to be cultured for 2 weeks to form clones, during which the medium was replaced every 2 days. Subsequently, 4\% paraformaldehyde was applied to fix the cells after washes with PBS. The Image J software (Bethesda, MD, USA) was used to count the clones dyed by crystal violet.

\section{Wound Healing Assay}

Cells were inoculated in a 6-well plate until the cell fusion rate reached $90 \%$. A wound was created on the confluent monolayer cells using a $10 \mu \mathrm{L}$ pipette tip, and cell fragments and floating cells were scoured off by PBS. The cells were then cultured with PT at different concentrations $(0,5,10,20 \mu \mathrm{M})$ for $48 \mathrm{~h}$ in a medium supplemented with $1 \%$ FBS. The 6-well plate was photographed under an optical microscope at specific time points $(0,48 \mathrm{~h})$, and the wound healing area was calculated using the Image $\mathrm{J}$ software (Bethesda, MD, USA). 
A

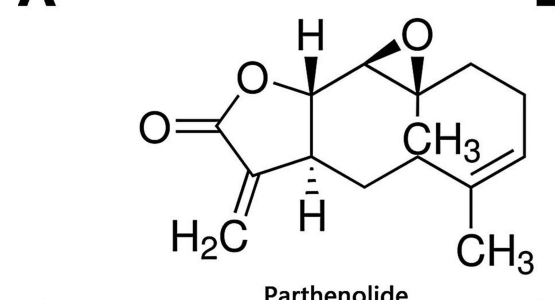

C

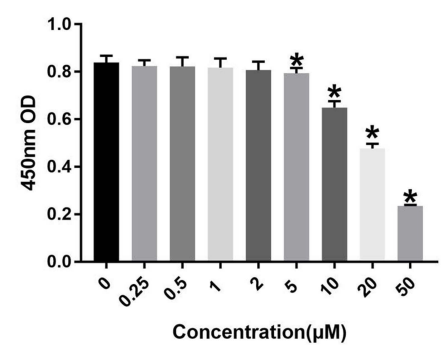

B

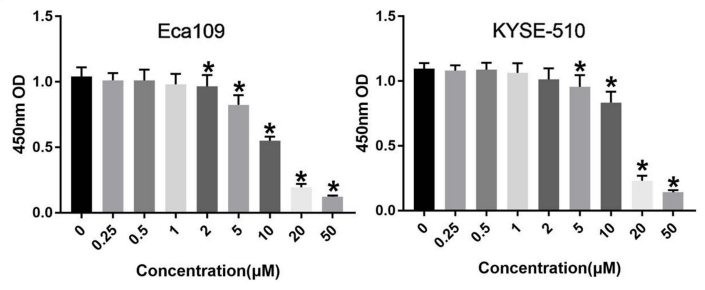

D

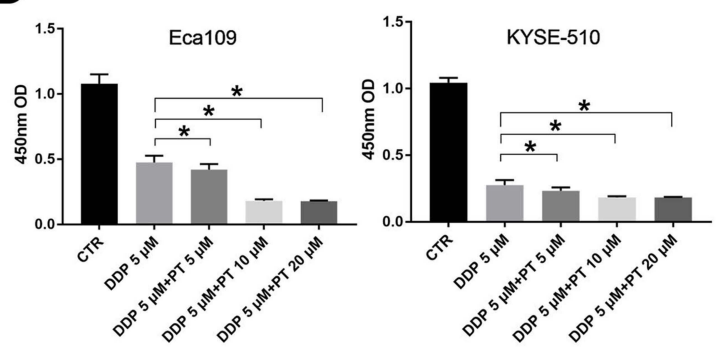

E

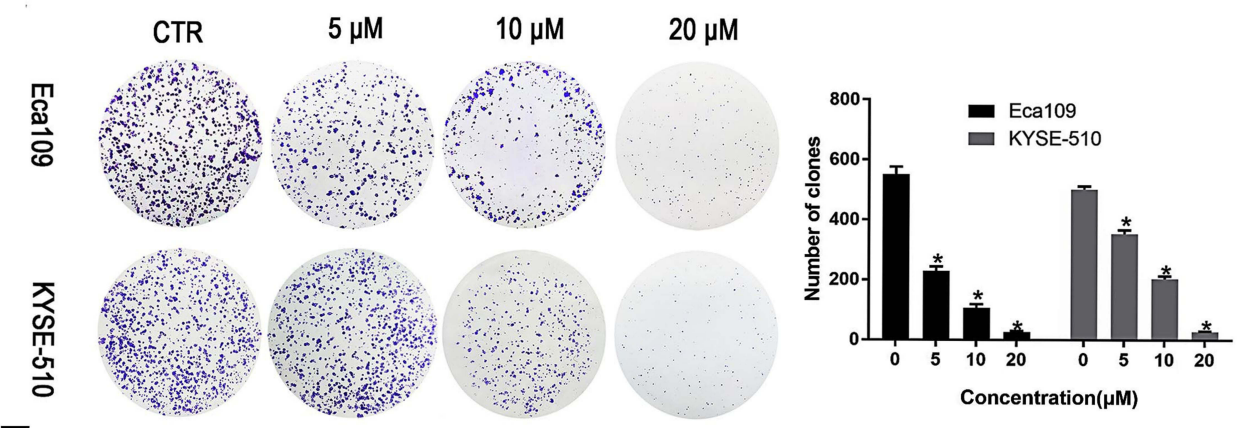

F

CTR

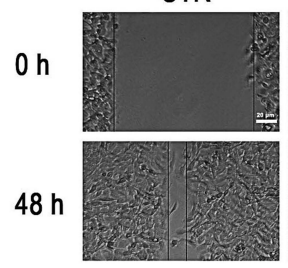

CTR

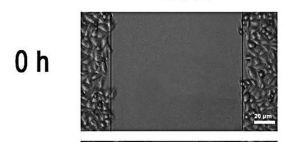

$48 \mathrm{~h}$

\section{$5 \mu \mathrm{M}$}

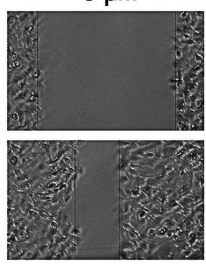

$5 \mu \mathrm{M}$

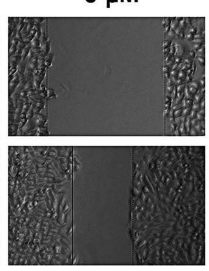

$10 \mu \mathrm{M}$

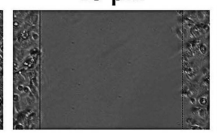

$20 \mu \mathrm{M}$
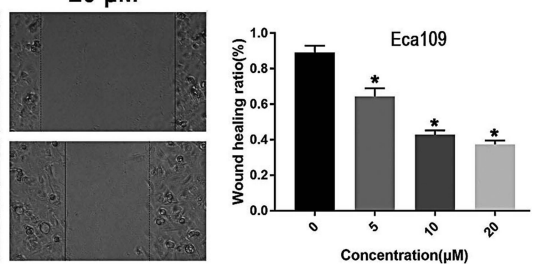

$10 \mu \mathrm{M}$

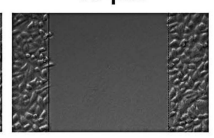

$20 \mu \mathrm{M}$
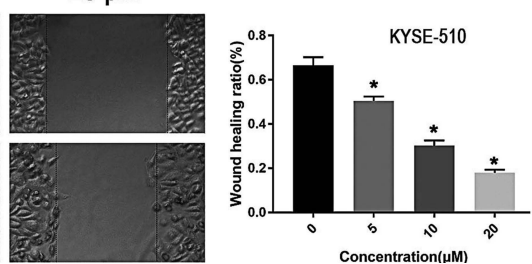

Figure I PT suppresses the proliferation and migration of ESCC cells. (A) The chemical structure of PT (molecular formula $\mathrm{C}_{15} \mathrm{H}_{20} \mathrm{O}_{3}$, molecular weight 284.32); (B) CCK-8 analysis for Eca 109 and KYSE-109 cells growth; (C) CCK-8 analysis for Het-IA growth; (D) Inhibitory effects of PT and DDP on Eca 109 and KYSE- 109 cells growth; (E) Colonyforming analysis for Eca 109 and KYSE-5 10 cells; (F) Wound healing analysis for Ecal 09 and KYSE-5I 0 cells migration. Data were represented as means \pm SD, $n=3$, *P $<0.05$.

\section{Cell Invasion Assay}

Cells were suspended in a serum-free medium, seeded in a Transwell upper chamber with Matrigel (Corning Incorporated) at $5 \times 10^{4}$ cells/well, and a medium containing 10\% FBS was added to the lower chamber. Cells in the upper compartment were incubated with different doses of PT $(0,5,10,20 \mu \mathrm{M})$ for $48 \mathrm{~h}$. Washing with PBS, fixation, and staining were performed in the 
same manner as in the clone formation assay. After wiping cells in the upper compartment with cotton swabs, five fields of view were randomly taken under the microscope to tally the number of invaded cells.

\section{Tube Formation Assay}

Each well of the 96-well plate was tiled with $50 \mu \mathrm{L}$ Matrigel (Corning Incorporated), standing at $37^{\circ} \mathrm{C}$ for 30 min, followed by seeding each well with HUVECs at 1000 cells/well. After $8 \mathrm{~h}$ of culture, the tube was photographed under an inverted microscope.

\section{ELISA Assay}

Eca109 and KYSE-510 cells were cultured with PT (0, 5, $10,20 \mu \mathrm{M})$ for $24 \mathrm{~h}$. The supernatant of the centrifuged culture medium was collected to detect VEGF secretion. The concentration of VEGF was determined according to the manufacturer's instructions provided with the VEGF ELISA kit used for the analysis (Proteintech group).

\section{Western Blot Analysis}

Extraction of the total cellular protein from cells treated with different doses of PT $(0,5,10,20 \mu \mathrm{M})$ for $48 \mathrm{~h}$ was carried out using the radio-immunoprecipitation buffer (RIPA, MultiSciences, Hangzhou, China) supplemented with protease inhibitors and phosphatase inhibitors. The protein concentration in the supernatant collected after centrifugation at $15,000 \mathrm{rpm}$ at $4^{\circ} \mathrm{C}$ for $30 \mathrm{~min}$ was measured using the BCA protein kit. The denatured protein was transferred to polyvinylidene difluoride (PVDF) membranes for antibody incubation (NF-kB, c-Fos, c-Jun, VEGF, GAPDH) at $4^{\circ} \mathrm{C}$ overnight after electrophoresis. Subsequently, the membrane was incubated with the secondary antibodies at room temperature for $2 \mathrm{~h}$ followed by two cycles of $30 \mathrm{~min}$ TBST washing. The luminol/enhancer reagent (New Cell and Molecular Biotech) was used to detect the bands.

\section{Tumor Xenograft Model}

Eca109 cells were digested with trypsin to yield a single cell suspension containing $1 \times 10^{7}$ cells $/ \mathrm{mL}$ in PBS. At a dose of $100 \mu \mathrm{L}$ per mice, the cell suspension was subcutaneously injected to the right side of each 4-week-old female Balb/c nu/nu mice. The two groups generated by random selection were injected intraperitoneally with DMSO and PT (4 mg/kg) three times a week, respectively. The body weight and tumor volume (v) of the mice were measured every 2 days. Each time the longest diameters (a) and shortest diameters (b) of the tumor were recorded, the tumor volume was presented as $v=1 / 2\left(a \times b^{2}\right)$, and the mice were sacrificed by cervical dislocation after 4 weeks.

\section{Immunohistochemistry}

Tumors and organs from the nude mice were prepared into paraffin sections for H\&E staining and immunohistochemical analysis. In short, the paraffin sections were deparaffinized until dehydration, then placed in citric acid buffer to complete antigen retrieval in the microwave and wait for natural cooling. Hydrogen peroxide (3\%) was used to block the endogenous peroxidase between the two cycles of PBS washing (5 min each). The primary antibody (antiNF-KB, anti-c-Fos, anti-c-Jun, anti-VEGF, anti-Ki67, and anti-CD31) was then added dropwise to the blocked sections and incubated overnight at $4^{\circ} \mathrm{C}$. The next day, the PBS cleaned sections were incubated with horseradish peroxidase- (HRP-) labeled secondary antibodies for 50 min and then washed again. 3,3-diaminobenzidine (DAB) staining was performed under the control of a microscope, and hematoxylin was used to stain the nucleus after the staining was terminated by running water. Finally, the sections were sealed with neutral gum after dehydration and transparency, and the images were collected and analyzed under the microscope. The microvessel number was determined by counting the CD-31 staining positive vessels within tumor tissues at $100 \times$ magnification.

\section{Statistical Analysis}

All data are presented as the mean \pm standard deviation (SD) of at least three independent experiments. Statistical analysis was performed using SPSS 17.0 software. Student's $t$-test was used to analyze the differences between the two sets of data. $\mathrm{P}<0.05$ was considered statistically significant.

\section{Results}

\section{Parthenolide Suppresses Cell}

Proliferation and Migration of ESCC Cells

To determine the effects of PT on the growth of human ESCC cells, various concentrations of PT were used to treat Eca109 and KYSE-510 cells for $48 \mathrm{~h}$ and the cytotoxic effects were evaluated by the CCK-8 assay. As shown in Figure 1B, the growth ability of Eca109 and Kyse-510 cells were significantly weakened by PT treatment in a dose-dependent manner. The IC50 value of PT for Eca109 and KYSE-510 cells were 
found to be approximately 10.3 and $13.3 \mu \mathrm{M}$ at $48 \mathrm{~h}$, as a result, 5, 10 and $20 \mu \mathrm{M}$ of PT was been used in the subsequent experiments. Whereafter, the effect of PT on the proliferation capacity of esophageal epithelial cells Het-1A was detected, and the results are shown in Figure 1C. PT also had an inhibitory effect on the proliferation of Het-1A, whereas the IC50 of PT for Het-1A was approximately $21.54 \mu \mathrm{M}$, which significantly higher than that on Eca109 and KYSE-510.

The anti-proliferation effects of PT $(5,10,20 \mu \mathrm{M})$ combined with DDP $(5 \mu \mathrm{M})$ were also evaluated on ESCC cells. The results in Figure 1D showed that DDP combined with PT led to a more effective suppression on the proliferative capacity of Eca109 and KYSE-510 compared with DDP alone.

In addition, the colony formation assay was used to investigate the effect of PT on ESCC cell growth. The results in Figure 1E show that compared to the control group, the number and size of colonies of Eca109 and KYSE-510 cells gradually decrease with the increasing concentration of PT.

Metastasis is the major cause of ESCC-related death among patients. Hence, the wound healing migration assay was conducted to investigate the influence of PT on ESCC cell migration ability. As shown in Figure 1F, the wound healing rate of Eca109 and KYSE-510 cells treated with PT for $48 \mathrm{~h}$ was significantly lower than that of the control group, and the inhibition was within a dose-dependent manner. These results indicate that PT could inhibit the viability and migration of ESCC cells.

\section{Parthenolide Inhibits Angiogenesis in vitro}

We next evaluated the activity of PT on angiogenesis, which plays a critical role in the progression and metastasis in ESCC. HUVECs were treated with different concentrations of PT for $24 \mathrm{~h}$. Subsequently, the proliferation, migration, invasion, and tube formation abilities of HUVECs were evaluated. As shown in Figure 2, the HUVEC cells proliferation, migration, invasion, and tube formation were all inhibited by PT treatment in a dosage-dependent manner. These results demonstrate that PT shows a marked anti-angiogenic effect.

\section{Parthenolide Inhibits VEGF Expression in ESCC Cells by Downregulating NF- $\kappa B$}

The competence of PT in inhibiting NF- $\mathrm{BB}$ has been reported in a variety of tumor cells. ${ }^{22,23}$ VEGF is the dominant regulator of angiogenesis. Therefore, we hypothesized that $\mathrm{PT}$ might regulate the expression of VEGF through the NF- $\mathrm{B}$ pathway. AP-1, a dimer complex transcriptional activator consists primarily of Fos and Jun proteins, was reported to be regulated by NF- $\kappa \mathrm{B}$ and interacts with $\mathrm{NF}-\kappa \mathrm{B}$ to cooperatively regulate the expression of target genes. ${ }^{24,25}$ In this study, Western blotting was conducted to detect the expression of NF- $\kappa \mathrm{B}, \mathrm{c}-\mathrm{Fos}$, c-Jun, and VEGF proteins in ESCC cells treated with PT. As shown in Figure $3 \mathrm{~A}$ and $\mathrm{B}$, the expression of $\mathrm{NF}-\kappa \mathrm{B}$, c-Fos, c-Jun, and VEGF was downregulated in Eca109 and KYSE-510 cells after incubation with PT for $24 \mathrm{~h}$. In addition, ELISA was conducted to analyze the secretion of VEGF by ESCC cells. Data from Figure 3C and $\mathrm{D}$ revealed that the expression of VEGF proteins in the culture supernatant of Eca109 and KYSE-510 cells reduced significantly with the increasing concentration of PT.

To gain further insight into the involvement of NF- $\mathrm{B}$ and AP-1 on the expression of VEGF, TNF- $\alpha(10 \mathrm{ng} / \mathrm{mL})$, an NF- $\mathrm{B}$ promoter, ${ }^{26}$ was used to treat Eca109 cells in the presence or absence of PT $(10 \mu \mathrm{M})$ for $24 \mathrm{~h}$. Data from Figure $3 \mathrm{E}$ showed that TNF- $\alpha$ treatment markedly induced the expression of $\mathrm{NF}-\kappa \mathrm{B}$, and also increased the expression of c-Fos, c-Jun, and VEGF in Eca109 cells. The PTinduced downregulation of c-Fos, c-Jun, and VEGF was partially recovered by TNF- $\alpha$. These results suggest that PT might inhibit ESCC cell-induced angiogenesis through the $\mathrm{NF}-\kappa \mathrm{B} / \mathrm{AP}-1$ pathway.

\section{Parthenolide Inhibits Tumor Growth and Tumor Angiogenesis in a Mouse Xenograft Model}

The mouse xenograft model established by Eca109 cells was used to explore the anti-tumor-growth and antiangiogenesis effect of PT in vivo. After 4 weeks of intraperitoneal injection of $4 \mathrm{mg} / \mathrm{kg}$ PT three times a week in nude mice, the tumor volume in the PT-treated group of nude mice was significantly smaller than that in the control group (Figure 4A and B). In addition, no significant difference in the bodyweight of nude mice was detected between the two groups (Figure 4C). Similar results from H\&E staining of paraffin sections of normal tissue (heart, liver, spleen, lung, and kidney) in both the groups also represented low toxicity of PT to normal organs (Figure 4D). 


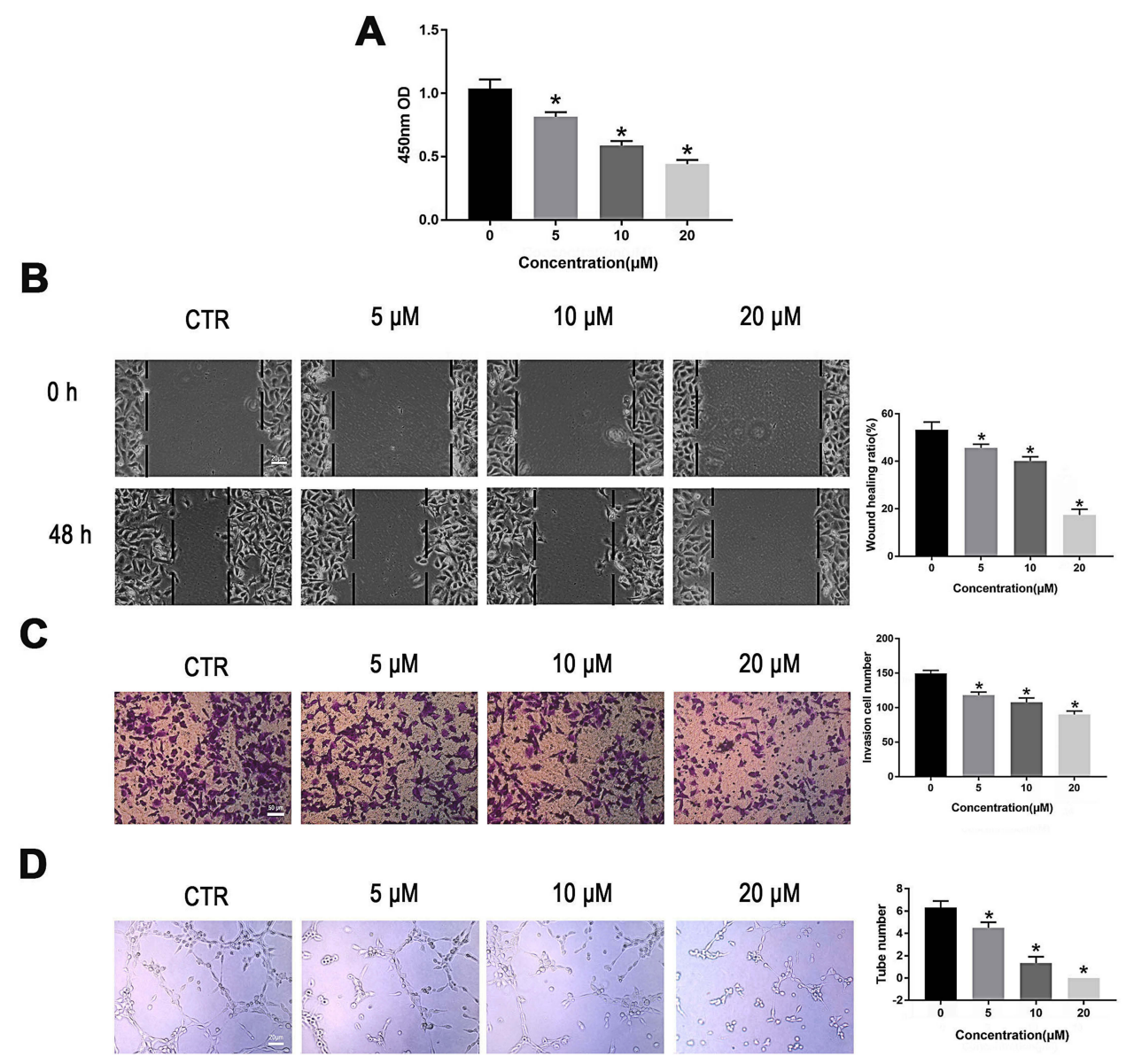

Figure 2 PT suppresses proliferation, migration, invasion and tube formation of HUVECs. (A) CCK-8 analysis for HUVECs proliferation; (B) Wound healing analysis for HUVECs migration; (C) Transwell Matrigel analysis for HUVECs invasion; (D) Tube formation analysis for HUVECs tube formation. Representative results and quantitative data of tube formation of HUVECs. All data were represented as means $\pm S D, n=3$, $* P<0.05$.

\section{Parthenolide Inhibits Expression of NF-} $\kappa B, A P-I$, and VEGF in the Tumor of

\section{Mouse Xenograft Model}

Ki67 is a nuclear antigen that is directly associated with cell proliferation. ${ }^{27}$ From Figure $5 \mathrm{~A}$, Ki67 staining of tumor sections reveals that the PT-treated groups have markedly less Ki67-positive cells than the control group. CD31 (PEMCAM1), a member of the immunoglobulin superfamily, has shown a crucial role as an immune marker in vascular-related tumors, and has also been widely applied to evaluate tumor angiogenesis. ${ }^{28,29}$ From Figure 5B, well-formed CD31-positive vessels within tumor tissues could be seen in these tumors. The microvessel density in the tumor tissues of PT-treated group was much lower than that in the control group, suggesting that angiogenesis in the mouse xenograft model was markedly inhibited by PT treatment. Moreover, the expression levels of NF- $\mathrm{B}$, c-Fos, c-Jun, and VEGF were suppressed by PT treatment in the xenograft tumors, in accordance with the in vitro results (Figure 5C).

\section{Discussion}

In recent years, many studies have discovered the antitumor effect of PT in a variety of cancers. ${ }^{15,17,19,20}$ In the present study, we uncovered the antitumor effect and the underlying mechanism of action of PT on ESCC. We demonstrated that PT could inhibit the proliferation and migration of Eca109 and KYSE-510 ESCC cells in vitro and inhibited the tumor growth of Eca109 ESCC xenograft model. Previous studies have reported that PT can produce a cytotoxic effect on tumor stem cells, while only has a slight effect on normal cells. ${ }^{30}$ In accordance with this, our results also showed that PT has a higher IC50 on normal esophageal epithelial cells compared to ESCC cells, indicating that PT is less toxic to normal cells. Furthermore, no marked bodyweight lose and no significant toxicity in the heart, liver, lung, kidney, and spleen of 
A
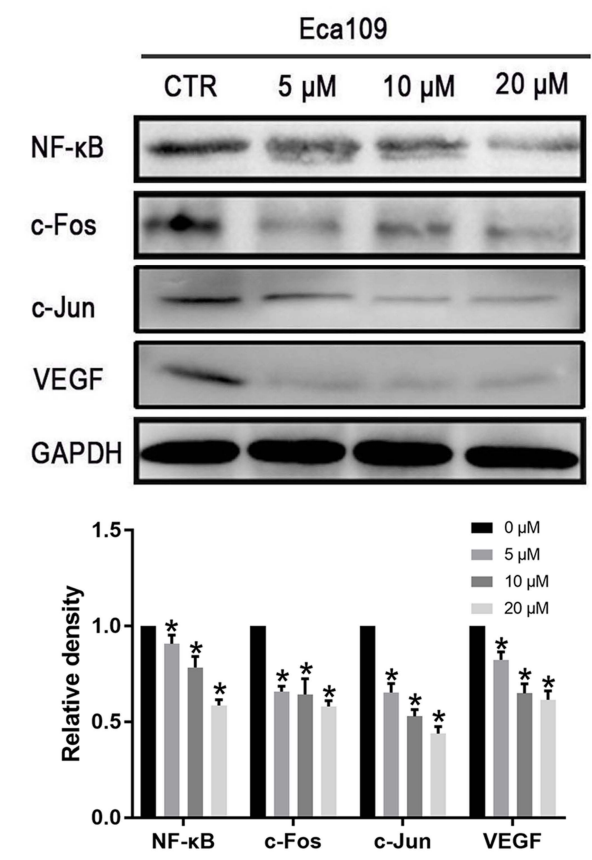

C

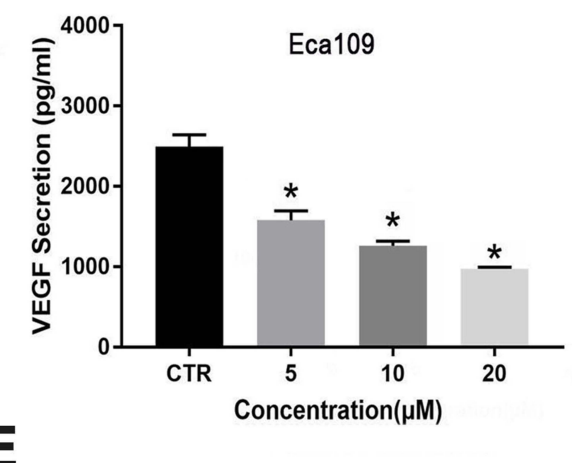

E

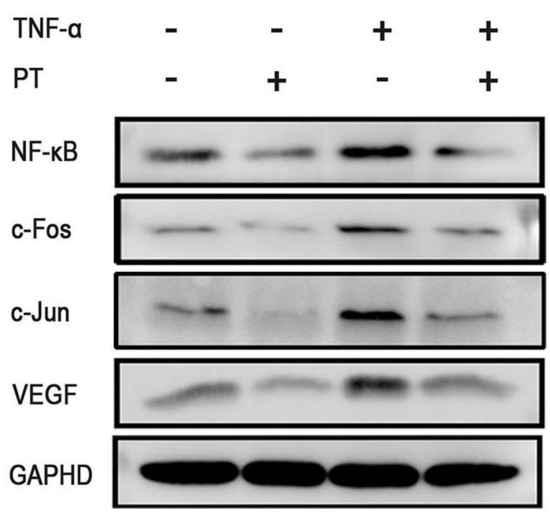

B
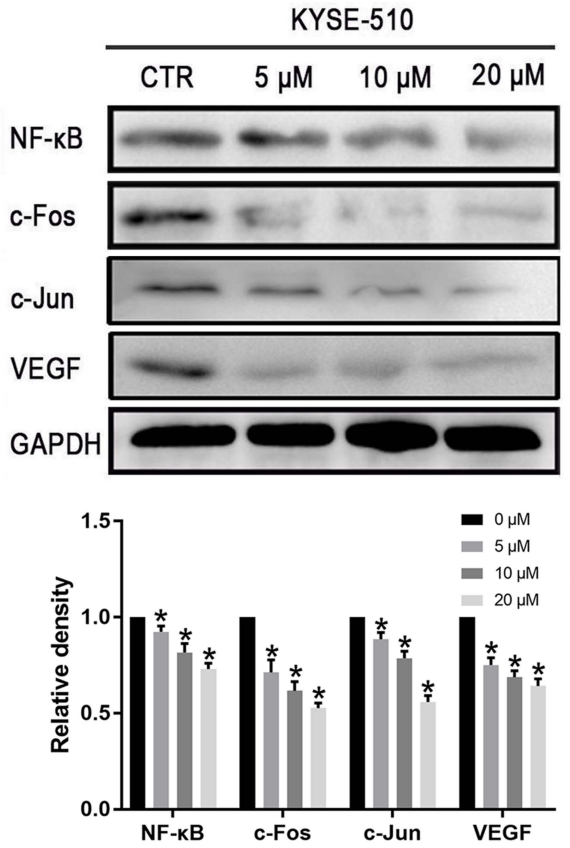

D
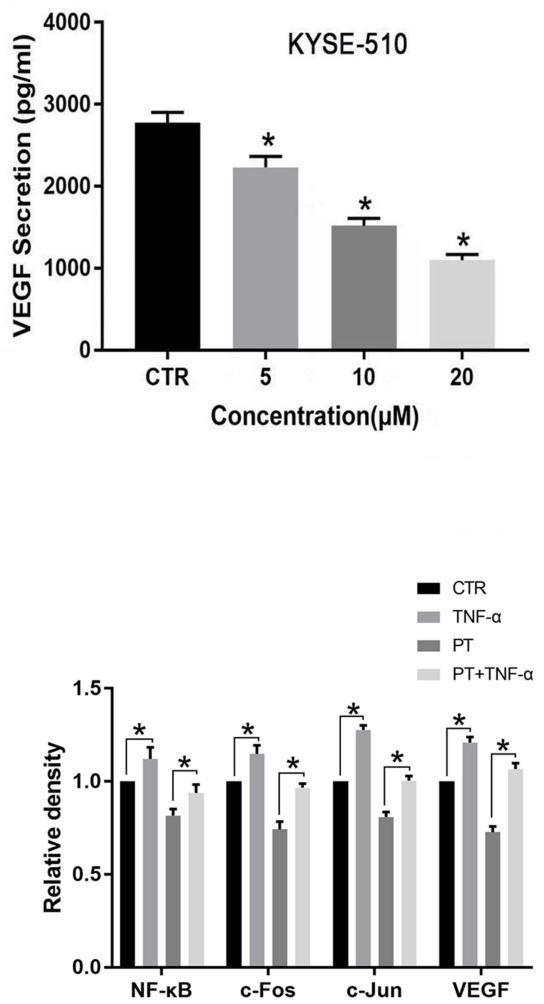

Figure 3 PT inhibits the expression of NF- $\mathrm{KB}, \mathrm{AP}-\mathrm{I}$ and VEGF in ESCC cells. Western blot analysis for the determination of the expression of NF- $\mathrm{KB}$, AP-I and VEGF in (A) Eca 109 and (B) KYSE-510 cells; ELISA analysis for the determination of the expression of VEGF in the culture medium of (C) Eca 09 and (D) KYSE-5I0 cells; (E) Western blot analysis for the determination of the expression of NF- $\kappa B$, c-Fos, c-Jun and VEGF in Ecal 09 cells treated with PT and/or TNF- $\alpha$. Data were represented as means \pm SD, $\mathrm{n}=3, * \mathrm{P}<0.05$ 
A

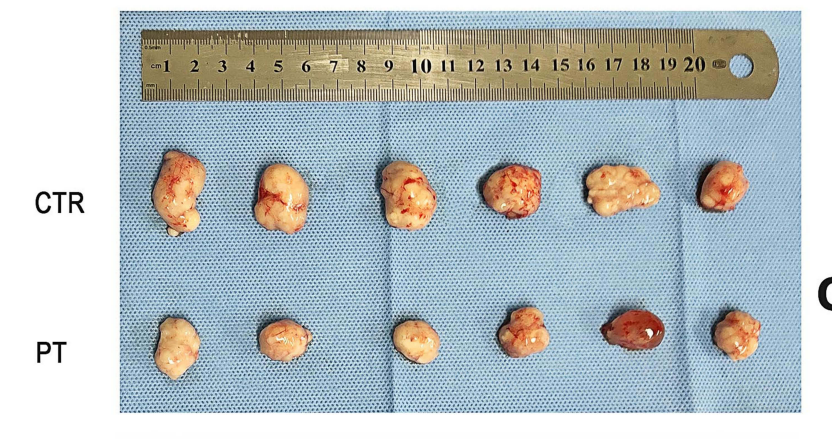

B

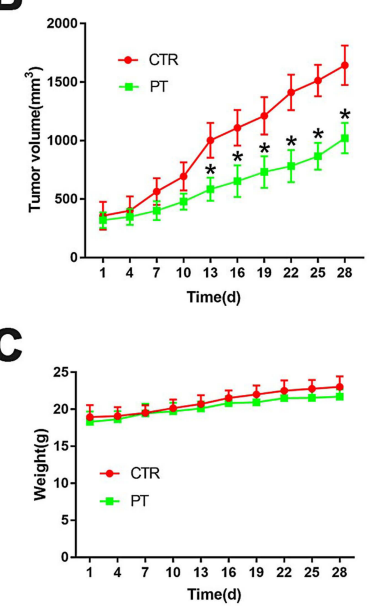

D
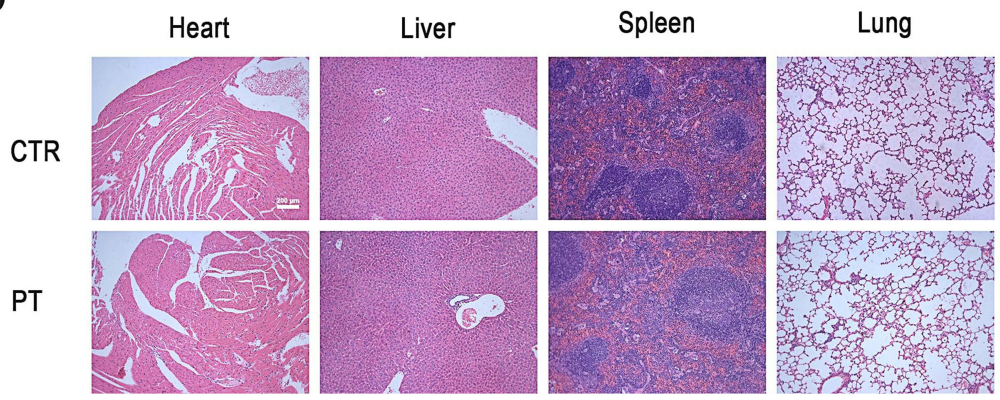

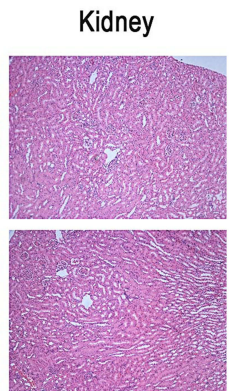

Figure 4 PT inhibited tumor growth in Eca 109 ESCC subcutaneous xenograft tumor model. (A) Representative picture showing subcutaneous tumor-bearing nude mice of control and PT-treated group; (B) Changes in tumor volume of nude mice during treatment; (C) Changes in body weight of nude mice during treatment; (D) Representative images of HE staining for normal tissues (heart, liver, spleen, lung and kidney). Subcutaneous tumor-bearing nude mice were intraperitoneally injected with PT 4 mg/kg body weight, thrice a week for 4 weeks. Data were represented as means $\pm S D, n=6, * P<0.05$.

mouse was observed following PT treatment. These findings suggest that PT might be a potent therapeutic agent in the treatment of ESCC that inhibits ESCC growth with low toxicity to animals.

PT has been shown to increase the sensitivity of some chemotherapeutic drugs in tumors, for instance, PT significantly enhances the sensitivity of the A549 lung cancer cell to Oxaliplatin through Inhibition of NF $-\kappa B,{ }^{31}$ and PT combined with DDP showed more effective inhibition on SGC-7901/DDP in gastric cancer cell. ${ }^{32}$ Here, PT in combination with DDP was used to treat ESCC cells, and the results showed that $\mathrm{PT}$ could significantly enhance the cell proliferation inhibition effect of DDP on Eca109 and KYSE-510 cells, indicating that PT and DDP have a synergistic effect on ESCC.

Angiogenesis is a fundamental prerequisite in the continued growth and metastasis of tumors. ${ }^{33}$ Inhibition of angiogenesis is therefore an effective strategy to inhibit tumor growth. In order to have more insight into the action of PT on ESCC, angiogenesis inhibition assays were conducted. We showed that PT could inhibit the HUVEC migration and tube formation in vitro and reduced density of microvessel in the ESCC xenograft model. Next, we investigated the underlying mechanism through which PT inhibits angiogenesis in ESCC. Studies have revealed that tumor-induced angiogenesis is mainly promoted by the production of pro-angiogenic factors, which are secreted by tumor cells. ${ }^{34}$ VEGF, the dominant regulator of angiogenesis, could be expressed and secreted by a number of tumor cells. ${ }^{35,36}$ VEGF could bind and activate the tyrosine kinase receptor VEGFR2 in endothelial cells, and subsequently stimulated the survival, proliferation, migration, and invasion of endothelial cells, which are critical steps in tumor angiogenesis., $57-39$ It has been demonstrated that PT exhibits its antitumor activity through inhibition of NF-кB. ${ }^{40}$ In addition, VEGF is a downstream molecular of NF-кB. ${ }^{41-43}$ In this study, we demonstrated that PT treatment could inhibit the expression of NF-кB and VEGF, in the two ESCC cell lines, which is similar to the part results reported in multiple myeloma, breast and colorectal cancer cells. ${ }^{20,44,45}$ In addition, we further investigated the effects of PT on VEGF secretion and 
A

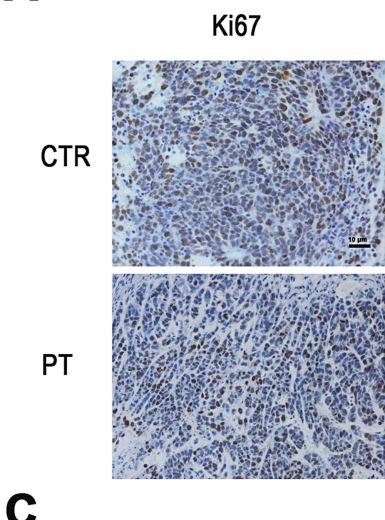

C

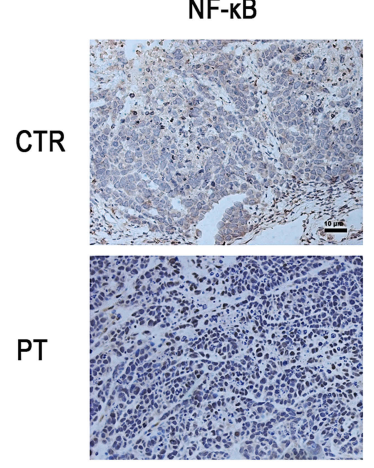

B

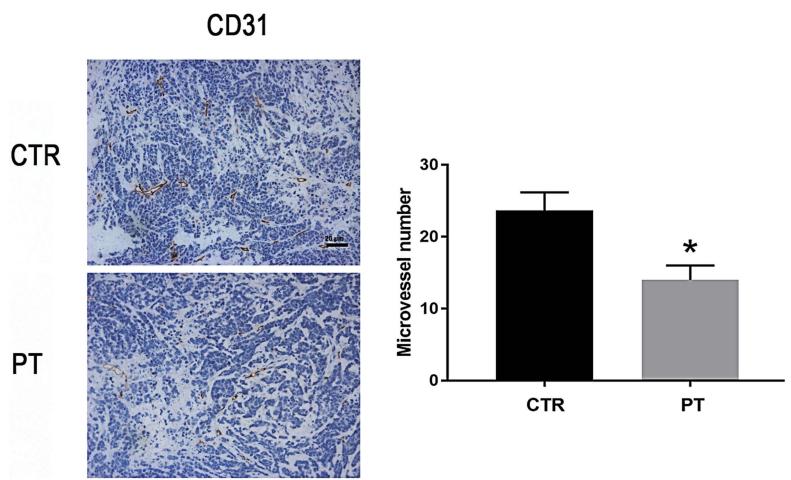

c-Jun

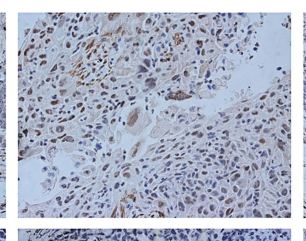

c-Fos

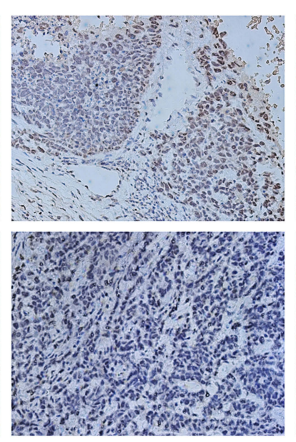

VEGF

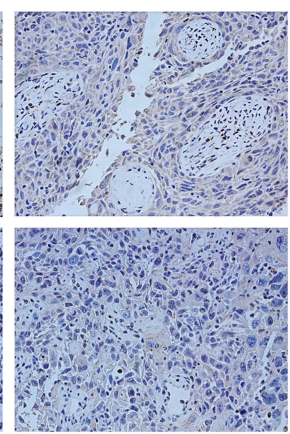

Figure 5 PT inhibits angiogenesis and down-regulates the expression of NF- $\mathrm{kB}, \mathrm{AP}-\mathrm{I}$ and VEGF in vivo. (A) Representative images of IHC staining for Ki-67 in the xenograft tumors; (B) Representative images of IHC staining for CD3I in the xenograft tumors and the determination of the antiangiogenesis effects of PT; (C) Representative images of IHC staining for NF- $\mathrm{KB}$, c-Fos, c-Jun and VEGF in the xenograft tumor model. $* \mathrm{P}<0.05$.

revealed that PT suppressed the secretion of VEGF in ESCC cells in a concentration-dependent manner, which is in concordance with the results of Kong et al and $\mathrm{Li}$ et al. ${ }^{46,47}$ These findings suggested that PT might exert its anti-angiogenic effects through inhibition of NF-KB induced VEGF expression in ESCC cells.

Previous studies have revealed that AP-1, a group of basic leucine zipper transcription factors, might be involved in the NF-KB regulated VEGF expression. ${ }^{48}$ Due to the multiple AP1-binding motifs within the VEGF promoter, ${ }^{49}$ we speculated that AP-1 might be involved in regulating the VEGF expression affected by PT. AP-1 is primarily composed of dimeric protein complexes formed by members of the Fos (c-Fos, FosB, Fra1, and Fra2), Jun (c-Jun, JunB, and JunD) and ATF families of proteins. ${ }^{50}$ The dominant forms of AP-1 are Fos/ Jun heterodimers, which are more stable and have a high affinity for binding to an AP-1 site than the other forms. The two major constituents of AP-1, c-Jun and c-Fos, are frequently overexpressed in multiple tumors, including ESCC. $^{51,52}$ c-Fos was considered as an immediate-early response gene and can be induced by activation of NF-KB. ${ }^{25}$ c-Fos has been shown to interfere with cell proliferation and induce cell transformation. $.^{53,54} \mathrm{c}-\mathrm{Jun}$ is a member of Ap-1, as well as the most potent transcriptional activator of Ap- $1 .{ }^{55}$ c-Jun was shown to regulate cellular proliferation and apoptosis. ${ }^{56,57}$ In the present study, we showed that PT treatment could decrease the expression c-Jun and c-Fos in ESCC cell lines and in the tumor of Eca109 ESCC xenograft model. Combined with the previous reports and the present data, we speculate that PT might regulate VEGF expression through the NF-kB/AP-1 pathway.

TNF- $\alpha$, an inflammatory cytokines, can promote cancer progression, including stimulate proliferation, survival, angiogenesis, and metastasis in most cancer cells. ${ }^{58,59}$ Several studies showed that NF- $\alpha$ could induce transcriptional activation of NF- $\kappa B .{ }^{60,61}$ To further demonstrate that mechanism of PT regulates VEGF expression, we treated the Eca109 cells with PT combined with TNF- $\alpha$. The data showed that TNF- $\alpha$ treatment activated the expression of NF-KB, c-Jun, c-Fos, as well as VEGF, and the PT-induced downregulation of the four proteins was partially recovered by TNF- $\alpha$. These results suggested that PT might inhibit ESCC cell-induced angiogenesis through the NF- $\mathrm{kB} / \mathrm{AP}-1 /$ VEGF pathway, but further studies are still required to verify 
the underlying mechanism of PT-induced inhibition of angiogenesis.

In summary, the present study demonstrated that PT appears to markedly inhibit the growth of ESCC cells in vitro and in vivo. PT could significantly inhibit ESCCinduced angiogenesis by reducing the expression of VEGF, possibly by negatively regulating the NF- $\mathrm{B} / \mathrm{AP}-$ 1 pathway. Our study provides a better understanding of the anti-tumor effects of PT and presents PT as a potent chemopreventive agent for the treatment of ESCC.

\section{Ethics Approval and Informed Consent}

All animal procedures were conducted in accordance with the guidelines of the National Institutes of Health and Use of Laboratory Animals. The animal experiments were approved by the Ethical Committee of Hunan Cancer Hospital (approval number: SBQLL-2017-11). Four-week-old nude mice (female) were used as xenograft animal models for the assessment of antitumor effects. The mice were housed in a pathogen-free controlled environment $\left(23-27^{\circ} \mathrm{C}\right.$ under a 12 $\mathrm{h}$ light/dark cycle) and allowed food and water ad libitum.

\section{Author Contributions}

All authors made substantial contributions to conception and design, acquisition of data, or analysis and interpretation of data; took part in drafting the article or revising it critically for important intellectual content; gave final approval of the version to be published; and agree to be accountable for all aspects of the work.

\section{Funding}

This study was financially supported by the Health and Family Planning Commission of Hunan Province (B20180545, C2019074), Natural Science Foundation of Hunan Province (2017JJ2173, 2019JJ50968, 2019JJ50358), and Fundamental Research Funds for the Central Universities of Central South University (502211903).

\section{Disclosure}

The authors report no conflicts of interest in this work.

\section{References}

1. Ferlay J, Soerjomataram I, Dikshit R, et al. Cancer incidence and mortality worldwide: sources, methods and major patterns in GLOBOCAN 2012. Int $J$ Cancer. 2015;136(5):E359-E386. doi:10.1002/ijc. 29210
2. Abnet CC, Arnold M, Wei WQ. Epidemiology of esophageal squamous cell carcinoma. Gastroenterology. 2017;154(2):360-373.

3. Pennathur A, Gibson MK, Jobe BA, Luketich JD. Oesophageal carcinoma. Lancet. 2013;381(9864):400-412. doi:10.1016/S01406736(12)60643-6

4. Liu Y, Xiong Z, Beasley A, D'Amico T, Chen XL. Personalized and targeted therapy of esophageal squamous cell carcinoma: an update. Ann N Y Acad Sci. 2016;1381(1):66-73. doi:10.1111/nyas.13144

5. Park MS, Dong SM, Kim BR, et al. Thioridazine inhibits angiogenesis and tumor growth by targeting the VEGFR-2/PI3K/mTOR pathway in ovarian cancer xenografts. Oncotarget. 2014;5 (13):4929-4934. doi:10.18632/oncotarget.2063

6. André T, Chastre E, Kotelevets L. et al. Tumoral angiogenesis: physiopathology, prognostic value and therapeutic perspectives. Rev Med Interne. 1998;904-913. doi:10.1016/S0248-8663(99)80063-0

7. Li CH, Xue JS, Shi SN, et al. Overexpression of IQGAP1 promotes the angiogenesis of esophageal squamous cell carcinoma through the AKT and ERK?mediated VEGF?VEGFR2 signaling pathway. Oncol Rep. 2018;40(3):1795-1802. doi:10.3892/or.2018.6558

8. Garcia J, Hurwitz HI, Sandler AB, et al. Bevacizumab (Avastin(R)) in cancer treatment: a review of 15 years of clinical experience and future outlook. Cancer Treat Rev. 2020;86:102017. doi:10.1016/j. ctrv.2020.102017

9. Ettinger DS, Aisner DL, Wood DE, et al. NCCN guidelines insights: non-small cell lung cancer, version 5.2018. J Natl Compr Canc Netw. 2018;16(7):807-821. doi:10.6004/jnccn.2018.0062

10. Cardoso F, Senkus E, Costa A, et al. 4th ESO-ESMO international consensus guidelines for Advanced Breast Cancer (ABC 4) †. Ann Oncol. 2018;29(8):1634-1657. doi:10.1093/annonc/mdy192

11. Nie K, Geng C, Zhang L, et al. Clinical observation of bevacizumab combined with S-1 in the treatment of pretreated advanced esophageal carcinoma. Chin Med Sci J. 2016;31(4):221-227. doi:10.1016/ s1001-9294(17)30004-4

12. Knight DW. Feverfew: chemistry and biological activity. Nat Prod Rep. 1995;12(3):271-276. doi:10.1039/np9951200271

13. Mathema VB, Koh YS, Thakuri BC, Sillanpaa M. Parthenolide, a sesquiterpene lactone, expresses multiple anti-cancer and anti-inflammatory activities. Inflammation. 2012;35(2):560-565. doi:10.1007/s10753-011-9346-0

14. Ghantous A, Sinjab A, Herceg Z, Darwiche N. Parthenolide: from plant shoots to cancer roots. Drug Discov Today. 2013;18(17-18):894-905. doi:10.1016/j.drudis.2013.05.005

15. D'Anneo A, Carlisi D, Lauricella M, et al. Parthenolide generates reactive oxygen species and autophagy in MDA-MB231 cells. A soluble parthenolide analogue inhibits tumour growth and metastasis in a xenograft model of breast cancer. Cell Death Dis. 2013;4 (10):e891. doi:10.1038/cddis.2013.415

16. Talib WH, Al Kury LT. Parthenolide inhibits tumor-promoting effects of nicotine in lung cancer by inducing P53 - dependent apoptosis and inhibiting VEGF expression. Biomed Pharmacother. 2018;107:1488-1495. doi:10.1016/j.biopha.2018.08.139

17. Liu W, Wang X, Sun J, Yang Y, Li W, Song J. Parthenolide suppresses pancreatic cell growth by autophagy-mediated apoptosis. Onco Targets Ther. 2017;10:453-461. doi:10.2147/OTT.S117250

18. Zhu SM, Park YR, Seo SY, Kim IH, Lee ST, Kim SW. Parthenolide inhibits transforming growth factor $\beta 1$-induced epithelialmesenchymal transition in colorectal cancer cells. Intest Res. 2019;17(4):527-536. doi:10.5217/ir.2019.00031

19. Talib WH, Al Kury LT. Parthenolide inhibits tumor-promoting effects of nicotine in lung cancer by inducing P53 - dependent apoptosis and inhibiting VEGF expression. Biomed Pharmacother. 2018;107:1488-1495.

20. Kim SL, Lee S-T, Trang K, et al. Parthenolide exerts inhibitory effects on angiogenesis through the downregulation of VEGF/ VEGFRs in colorectal cancer. Int $J$ Mol Med. 2014;33 (5):1261-1267. doi:10.3892/ijmm.2014.1669 
21. Li L, Li D. Apoptosis of human esophageal cancer cell EC9706 induced by parthenolide. China J Mod Med. 2010;20:2658-2661.

22. Liao K, Xia B, Zhuang Q-Y, et al. Parthenolide inhibits cancer stemlike side population of nasopharyngeal carcinoma cells via suppression of the NF- $\mathrm{kB} / \mathrm{COX}-2$ pathway. Theranostics. 2015;5 (3):302-321. doi:10.7150/thno.8387

23. Nakabayashi H, Shimizu K. Involvement of Akt/NF-kB pathway in antitumor effects of parthenolide on glioblastoma cells in vitro and in vivo. BMC Cancer. 2012;12(1):453. doi:10.1186/1471-2407-12453

24. Herbein G, Varin A, Fulop T. NF-kappaB, AP-1, zinc-deficiency and aging. Biogerontology. 2006;7(5-6):409-419. doi:10.1007/s10522006-9056-4

25. Fujioka S, Niu J, Schmidt C, Sclabas GM, Chiao PJ. NF-kappaB and AP-1 connection: mechanism of NF-kappaB-dependent regulation of AP-1 activity. Mol Cell Biol. 2004;7806-7819. doi:10.1128/ MCB.24.17.7806-7819.2004

26. Fortenberry JD, Owens ML, Chen NX, Brown LA. S-nitrosoglutathione inhibits TNF-alpha-induced NFkappaB activation in neutrophils. Inflamm Res. 2001;50(2):89-95. doi:10.1007/ s000110050729

27. Justyna Z, Konrad Z, Katarzyna G-U. Expression of chosen cell cycle and proliferation markers in pancreatic intraepithelial neoplasia Gastroenterol Rev. 2018;13(2):118-126. doi:10.5114/pg.2018.75824

28. Razavi SM, Yahyaabadi R. Comparative study of correlation between angiogenesis markers (CD31) and Ki67 marker with behavior of aggressive and nonaggressive central giant cell granuloma with immunohistochemistry technique. Asian Pac $J$ Cancer Prev. 2018;19(8):2279-2283. doi:10.22034/APJCP.2018.19.8.2279

29. Wang D, Stockard CR, Harkins L, et al. Immunohistochemistry in the evaluation of neovascularization in tumor xenografts. Biotech Histochem. 2008;83(3-4):179-189. doi:10.1080/ 10520290802451085

30. Guzman ML, Rossi RM, Karnischky L, et al. The sesquiterpene lactone parthenolide induces apoptosis of human acute myelogenous leukemia stem and progenitor cells. Blood. 2005;105(11):4163-4169. doi:10.1182/blood-2004-10-4135

31. Fang LJ, Shao XT, Wang S, Lu GH, Xu T, Zhou JY. Sesquiterpene lactone parthenolide markedly enhances sensitivity of human A549 cells to low-dose oxaliplatin via inhibition of NF-kappaB activation and induction of apoptosis. Planta Med. 2010;76(3):258-264. doi:10.1055/s-0029-1186083

32. Sohma I, Fujiwara Y, Sugita Y, et al. Parthenolide, an NF- $\kappa B$ inhibitor, suppresses tumor growth and enhances response to chemotherapy in gastric cancer. Cancer Genomics Proteomics. 2011;8 (1):39-47.

33. Bielenberg DR, Zetter BR. The contribution of angiogenesis to the process of metastasis. Cancer J. 2015;21(4):267-273. doi:10.1097/ PPO.0000000000000138

34. Gupta MK. Mechanism and its regulation of tumor-induced angiogenesis. World $J$ Gastroenterol. 2003;9(6):1144-1155. doi:10.3748/wjg.v9.i6.1144

35. van de Schootbrugge C, Bussink J, Span PN, et al. $\alpha \mathrm{B}$-crystallin stimulates VEGF secretion and tumor cell migration and correlates with enhanced distant metastasis in head and neck squamous cell carcinoma. BMC Cancer. 2013;13:128.

36. Li R, Qi Y, Jiang M, et al. Primary tumor-secreted VEGF induces vascular hyperpermeability in premetastatic lung via the occludin phosphorylation/ubiquitination pathway. Mol Carcinog. 2019;58 (12):2316-2326. doi:10.1002/mc. 23120

37. Su CH, Wu YJ, Chang CY, et al. The increase of VEGF secretion from endothelial progenitor cells post ultrasonic VEGF gene delivery enhances the proliferation and migration of endothelial cells. Ultrasound Med Biol. 2013;39(1):134-145. doi:10.1016/j. ultrasmedbio.2012.08.018
38. Melincovici CS, Boşca AB, Şuşman S, et al. Vascular endothelial growth factor (VEGF) - key factor in normal and pathological angiogenesis. Rom J Morphol Embryol. 2018;59(2):455-467.

39. Dvorak HF. Vascular permeability factor/vascular endothelial growth factor: a critical cytokine in tumor angiogenesis and a potential target for diagnosis and therapy. J Clin Oncol. 2002;20(21):4368-4380. doi:10.1200/JCO.2002.10.088

40. Oka D, Nishimura K, Shiba M, et al. Sesquiterpene lactone parthenolide suppresses tumor growth in a xenograft model of renal cell carcinoma by inhibiting the activation of NF-kappaB. Int $J$ Cancer. 2007;120(12):2576-2581. doi:10.1002/ijc.22570

41. Liu JY, Zeng QH, Cao PG, et al. RIPK4 promotes bladder urothelial carcinoma cell aggressiveness by upregulating VEGF-A through the NF-kappaB pathway. $B r \quad J$ Cancer. 2018;118(12):1617-1627. doi:10.1038/s41416-018-0116-8

42. Zhang B, Wang D, Ji TF, Shi L, Yu JL. Overexpression of IncRNA ANRIL up-regulates VEGF expression and promotes angiogenesis of diabetes mellitus combined with cerebral infarction by activating NFкB signaling pathway in a rat model. Oncotarget. 2017;8 (10):17347-17359. doi:10.18632/oncotarget.14468

43. Tino AB, Chitcholtan K, Sykes PH, Garrill A. Resveratrol and acetylresveratrol modulate activity of VEGF and IL-8 in ovarian cancer cell aggregates via attenuation of the NF- $\mathrm{BB}$ protein. $J$ Ovarian Res. 2016;9(1):84. doi:10.1186/s13048-016-0293-0

44. Kong FC, Zhang JQ, Zeng C, et al. Inhibitory effects of parthenolide on the activity of NF-kappaB in multiple myeloma via targeting TRAF6. J Huazhong Univ Sci Technolog Med Sci. 2015;35 (3):343-349. doi:10.1007/s11596-015-1435-0

45. Li C, Guo S, Shi T. Role of NF-kappaB activation in matrix metalloproteinase 9, vascular endothelial growth factor and interleukin 8 expression and secretion in human breast cancer cells. Cell Biochem Funct. 2013;31(3):263-268. doi:10.1002/cbf.2899

46. Kong F, Chen Z, Li Q, et al. Inhibitory effects of parthenolide on the angiogenesis induced by human multiple myeloma cells and the mechanism. J Huazhong Univ Sci Technolog Med Sci. 2008;28 (5):525-530. doi:10.1007/s11596-008-0508-8

47. Li CJ, Guo SF, Shi TM. Culture supernatants of breast cancer cell line MDA-MB-231 treated with parthenolide inhibit the proliferation, migration, and lumen formation capacity of human umbilical vein endothelial cells. Chin Med J. 2012;125(12):2195-2199.

48. Schmidt D, Textor B, Pein OT, et al. Critical role for NF-kappaBinduced JunB in VEGF regulation and tumor angiogenesis. EMBO J. 2007;26(3):710-719. doi:10.1038/sj.emboj.7601539

49. Tischer E. The human gene for vascular endothelial growth factor: multiple protein forms are encoded through alternative exon splicing. J Biol Chem. 1991;266:11947-11954.

50. Leaner VD, Kinoshita I, Birrer MJ. AP-1 complexes containing cJun and JunB cause cellular transformation of Rat la fibroblasts and share transcriptional targets. Oncogene. 2003;22(36):5619-5629. doi:10.1038/sj.onc. 1206644

51. Wu MY, Zhuang CX, Yang HX, Liang YR. Expression of Egr-1, c-fos and cyclin D1 in esophageal cancer and its precursors: an immunohistochemical and in situ hybridization study. World J Gastroenterol. 2004;10(4):476-480. doi:10.3748/wjg.v10.i4.476

52. Trop-Steinberg S, Azar Y. AP-1 expression and its clinical relevance in immune disorders and cancer. Am J Med Sci. 2017;353 (5):474-483. doi:10.1016/j.amjms.2017.01.019

53. Yoo SM, Lee CJ, An HJ, et al. RSK2-mediated ELK3 activation enhances cell transformation and breast cancer cell growth by regulation of c-fos promoter activity. Int J Mol Sci. 2019;20(8). doi:10.3390/ijms20081994

54. Wang Q, Liu H, Wang Q, et al. Involvement of c-Fos in cell proliferation, migration, and invasion in osteosarcoma cells accompanied by altered expression of Wnt2 and Fzd9. PLoS One. 2017;12(6): e0180558. doi:10.1371/journal.pone. 0180558 
55. Kappelmann M, Bosserhoff A, Kuphal S. AP-1/c-Jun transcription factors: regulation and function in malignant melanoma. Eur $J$ Cell Biol. 2014;93(1-2):76-81. doi:10.1016/j.ejcb.2013.10.003

56. Wang D, Wang J, Ding N, et al. MAGE-A1 promotes melanoma proliferation and migration through C-JUN activation. Biochem Biophys Res Commun. 2016;473(4):959-965. doi:10.1016/j. bbrc.2016.03.161

57. Gao GY, Ma J, Lu P, Jiang X, Chang C. Ophiopogonin B induces the autophagy and apoptosis of colon cancer cells by activating JNK/ c-Jun signaling pathway. Biomed Pharmacother. 2018;108:1208-1215. doi:10.1016/j.biopha.2018.06.172

58. Balkwill F. TNF-alpha in promotion and progression of cancer. Cancer Metastasis Rev. 2006;25(3):409-416. doi:10.1007/s10555006-9005-3
59. Wang Y, Xu J, Zhang X, et al. TNF-alpha-induced LRG1 promotes angiogenesis and mesenchymal stem cell migration in the subchondral bone during osteoarthritis. Cell Death Dis. 2017;8(3):e2715. doi:10.1038/cddis.2017.129

60. Remels AH, Gosker HR, Verhees KJ, Langen RC, Schols AM. TNFalpha-induced NF-kappaB activation stimulates skeletal muscle glycolytic metabolism through activation of HIF-1alpha. Endocrinology. 2015;156(5):1770-1781. doi:10.1210/en.2014-1591

61. Kim M, Jung K, Kim IS, et al. TNF-alpha induces human neural progenitor cell survival after oxygen-glucose deprivation by activating the NF-kappaB pathway. Exp Mol Med. 2018;50(4):14. doi:10.1038/s12276-018-0033-1

\section{Publish your work in this journal}

OncoTargets and Therapy is an international, peer-reviewed, open access journal focusing on the pathological basis of all cancers, potential targets for therapy and treatment protocols employed to improve the management of cancer patients. The journal also focuses on the impact of management programs and new therapeutic agents and protocols on patient perspectives such as quality of life, adherence and satisfaction. The manuscript management system is completely online and includes a very quick and fair peer-review system, which is all easy to use. Visit http://www.dovepress.com/ testimonials.php to read real quotes from published authors. 